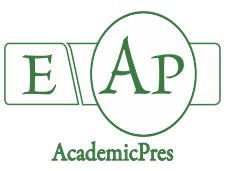

Zhou C et al. (2021)

Notulae Botanicae Horti Agrobotanici Cluj-Napoca

Volume 49, Issue 2, Article number 12314

DOI: $10.15835 /$ nbha49212314

Research Article

\title{
Light-emitting diode spectra modify nutritional status, physiological response, and secondary metabolites in Ficus hirta and Alpinia oxyphylla
}

\section{Changwei ZHOU ${ }^{1}$, Chongfei SHANG ${ }^{1}$, Feiyu $\mathrm{CHEN}^{1}$, Junzhou BAOㄹ, Lifei $\mathrm{YU}^{1 *}$, Peng GUO ${ }^{2 *}$}

\author{
${ }^{1}$ College of Life Science, Guizhou University, Guiyang 550025, China; changwei.1981@163.com; 18275128026@163.com; \\ fiona_fychen@163.com;1120025822@qq.com;gdyulifei@163.com (*corresponding author) \\ ${ }^{2}$ Environment and Resources College, Dalian Nationalities University, Dalian 116600, China; \\ gp@dlnu.edu.cn (*corresponding author)
}

\begin{abstract}
Lighting spectrum is one of the key factors that determine biomass production and secondarymetabolism accumulation in medicinal plants under artificial cultivation conditions. Ficus hirta and Alpinia oxyphylla seedlings were cultured with blue ( $10 \%$ red, $10 \%$ green, $70 \%$ blue), green ( $20 \%$ red, $10 \%$ green, $30 \%$ blue), and red-enriched (30\% red, $10 \%$ green, $20 \%$ blue) lights in a wide bandwidth of 400-700 nm. F. hirta seedlings had lower diameter, fine root length, leaf area, biomass, shoot nutrient $(\mathrm{N})$ and phosphorus concentrations in the blue-light spectrum compared to the red- and green-light spectra. In contrast, $A$. oxyphylla seedlings showed significantly higher concentrations of foliar flavonoids and saponins in red-light spectrum with rare responses in $\mathrm{N}$, chlorophyll, soluble sugars, and starch concentrations. F. hirta is easily and negatively impacted by blue-light spectrum but $A$. oxyphylla is suitably used to produce flavonoid and saponins in red-light spectrum across a wide bandwidth.
\end{abstract}

Keywords: chlorophyll; flavonoid; light-emitting diode; medicinal plants; saponin; non-structural carbohydrate

\section{Introduction}

Medicinal plants are cultivated and developed as a primary source of health care for thousands of years due to their pharmaceutical and therapeutic applications (World Health Organization, 2013). According to the World Health Organization (WHO) report on traditional medicine strategy, about $70 \%$ of the world population relies on traditional medicines and $80 \%$ of that are from developing countries (World Health Organization, 2013). The demand for medicinal plant production is increasing with the development of traditional and complementary medicine, but the plant material supply cannot meet this demand solely through traditional cultivation methods. Indoor farming is an excellent solution to meet the increasing demands at low electricity costs and precise water applications ( Rehman et al., 2017; Pennisi et al., 2020). Light 
intensity can be adjusted to best meet the demand of medicinal plant production because photosynthesis is related to water uptake efficiency, but at the cost of electrical power.

Light is the most important physical factor in an indoor plant factory because it affects plant growth and physiology, and impacts the sustainability of the production system. The development of semiconductor lighting contributes to the wide use of light emitting diodes (LED) in plant production. Being able to determine the amount of photons emitted at a given bandwidth gives LED illuminators more chances to be shown in photobiology studies than those with fixed wavelength characteristics (such as high-pressure sodium lamps) ( $\mathrm{Li}$ et al., 2018; Luo et al., 2020; Wei et al., 2020a; Wei et al., 2020b). Bandwidths in blue-light (400-500 nm) and red-light $(600-700 \mathrm{~nm})$ fall in the range that is preferred by chlorophylls. Both blue-light and red-lights are absorbed by chlorophyll a (Chl-a), which has absorption peaks at $430 \mathrm{~nm}$ and $665 \mathrm{~nm}$, and by chlorophyll b (Chl-b) at $453 \mathrm{~nm}$ and $642 \mathrm{~nm}$ (Landi et al., 2020). Carotenoids work with chlorophylls by channelling photons and dissipating excess light energy. Less than half of green-light $(500-600 \mathrm{~nm})$ are reflected by chloroplasts while the rest is absorbed by pigments or transmitted to shaded parts of the plant (Nishio, 2001; Terashima et al., 2009). Therefore, wavelengths in red- and blue-lights are mostly used for the design in different proportional ratios while fewer ones used to test the effects of the green-light spectrum on plant response (Luo et al., 2020).

Empirical data reveals that red-light benefits carbon dioxide $\left(\mathrm{CO}_{2}\right)$ assimilation rate, while green- and blue-lights impair $\mathrm{CO}_{2}$ assimilation in low and moderate to high light conditions, respectively (Landi et al., 2020). A large number of studies have tested the effects of different light wavelengths on morphological growth, dry mass accumulation, gas exchange, and photosynthesis ( Kang et al., 2016; Claypool and Lieth, 2020; Yan et al., 2020). Results from these studies have limited application meaning unless they were tested in a widebandwidth spectrum (Landi et al., 2020). Sunlight has a natural spectrum in a wide range of wavelengths (Wei et al., 2019). Studies have detected how lights in a wide-bandwidth affect plant growth (Wang et al., 2020; Wei et al., 2020a; Wei et al., 2020b), production, photosynthesis (Li et al., 2018; Luo et al., 2020), and nutritional uptake and utilization (Zhao et al., 2019; Wang et al., 2020; Wei et al., 2020a; Wei et al., 2020b). The main purpose of these studies was to obtain maximum yields from plants with high growth efficiency and are subjected to some special spectrum. Results demonstrated that red-light promoted shoot growth and biomass accumulation, and thus, would lead to nutrient dilution if no additional supply was given. Blue-light light promoted phosphorus $(\mathrm{P})$ uptake and diameter growth. Therefore, the change in light spectrum can modify nutrient uptake and status, which may further impact plant morphology and dry mass production. Quite less is known about the effects of wide-bandwidth light on secondary metabolites in medicinal plants.

Secondary metabolites are key compounds to extract from medicinal plants. They are well known as phytochemicals which are synthesized and accumulated in plant organs to counter and give protection against biotic stressors (Holopainen et al., 2018). Since light is essential for plants, low light can be considered as a stressor. However, low light is also a signal to promote the synthesis of secondary metabolites in medicinal plants. In shaded conditions, the decline in red-light wavelengths is a key factor that affects the production of secondary metabolites. In immediate sunlight, blue-light wavelengths act as high-energy radiation that elicit plants to protect their cells with pigments such as flavonoids and saponins ( Watcharatanon et al., 2019; Pennisi et al., 2020). Therefore, the responses of carbon (C)-assimilation related parameters to lighting spectra would be different from phytochemicals.

The plant Ficus hirta is a perennial shrub that is taken as traditional medicine for the treatment of weakness, puffiness, hepatitis, and rheumatism (Ya et al., 2010). The plant Alpinia oxyphylla is a perennial herb of Zingiberaceae whose extracts have pharmacological activities including neuroprotective capacity, antioxidant capacity, and anti-tumour capacity (Niu et al., 2020). Both species are widely distributed in southern parts of China. Flavonoids are one of the most frequently isolated secondary metabolites from the leaves of these two plants ( Ya et al., 2010; Niu et al., 2020). Although saponin content is rarely found in the leaves of these two plants, they are usually positively related to flavonoid content (Bhardwaj et al., 2019; Stankovic et al., 2019; Zu et al., 2020). The object of this study was to determine the effect of lighting spectra 
on the synthesized performance of medicinal plants. F. hirta and $A$. oxyphylla seedlings were raised as comparable materials exposed to different wide-bandwidth lights. We hypothesized that: (i) seedlings in redlight had highest shoot growth and nutrient utilization, while those in green-light had the lowest; (ii) greenlight elicited the highest concentration of secondary metabolism.

\section{Materials and Methods}

\section{Study site and plant material}

F. hirta and A. oxyphylla seeds were supplied from a nursery in Guizhou University (26 $24^{\prime} \mathrm{N}, 106^{\circ} 40^{\prime}$ E) and sent to the Laboratory of College of Life Science in Guizhou University for the experiment. The indoor environment blocked off sunlight, and all illumination for plant growth derived from artificial lighting. No strong wind flow was allowed to pass through the laboratory, but ventilation was used when it was necessary to promote air exchange and to adjust indoor temperatures.

In April 2019, seeds were sterilized in 0.5\% (w/w) potassium permanganate for $30 \mathrm{~min}$ and soaked in water at indoor temperatures for $24 \mathrm{~h}$. Cleaned seeds were germinated in mashed peat at a constant temperature of $36 \pm 1{ }^{\circ} \mathrm{C}$ with a relative humidity $(\mathrm{RH})$ of $85 \%$. The germination of $A$. oxyphylla was faster than that of $F$. hirta, but germination was terminated at the same time for both species when the aerial organ of $F$. hirta had grown to be long and strong enough. In mid-April of 2019, plantlets of both species were planted in cavities $(13 \mathrm{~cm} \times 7 \mathrm{~cm}$, height $\times$ top-diameter $)$ in cultivating trays filled with commercial growth media produced from peat, perlite, and spent-mushroom residues in volumetric proportions of 55:25:20 (Mashiro-Dust ${ }^{\mathrm{TM}}$, Zhiluntuowei A\&F S\&T Inc., Changchun, China). Thirty-two cavities were embedded in a planting tray in a $4 \times 8$ arrangement, but only 16 of them were used for plantlet transplant in a $14 \mathrm{~cm} \times 14 \mathrm{~cm}$ spacing. Four plantlets were placed in one cavity and only one of them was left for the experiment to ensure that all trays would maintain the same number of seedlings in an even placement. A total of 576 plantlets were transplanted to nine trayed cavities for one species and 1,152 plantlets were cultivated in total.

\section{Seedling cultivation and spectra treatment}

Trays were watered to full capacity with additional substrates covering the surface where root cavity volume was compacted by soaking. Trays were maintained for $12 \mathrm{~h}, 45 \mathrm{~cm}$ beneath high-pressure sodium (HPS) lamps, at a photosynthetic photon flux density (PPFD) of about $70 \mu \mathrm{mol} \mathrm{m} \mathrm{m}^{-2} \mathrm{~s}^{-1}$ on the surface. After another 12-h of dark time, trays of seedlings were placed in a tank of water at a depth of $3 \mathrm{~cm}$ for sub-irrigation (Wan et al., 2019; Wan et al., 2020). Tanks were subsequently placed on the floor of growing chambers $(0.5 \mathrm{~m}$ $\times 0.5 \mathrm{~m} \times 1.5 \mathrm{~m}$, height $\times$ width $\times$ length $)$ and three chambers were comprised by an iron shelf $(2.0 \mathrm{~m} \times 0.5 \mathrm{~m}$ $\times 1.5 \mathrm{~m}$, height $\times$ width $\times$ length) (Wei et al., 2020b). Two tanks with trayed seedlings were placed on one floor and each tanked tray contained one species. Therefore, six trays of seedlings were cultivated in one shelf with three trays per species.

A light-emitting diode (LED) panel $(0.5 \mathrm{~m} \times 1.2 \mathrm{~m}$, width $\times$ length) (Pudao Photoelectricity, Zhiluntuowei A\&F S\&T., Inc., Changchun, China) was equipped to the ceiling of a chamber to supply different spectra of light for seedlings. One hundred diodes were embedded on the panel in a $2 \mathrm{~cm} \times 2 \mathrm{~cm}$ spacing. Every diode was designed to emit a random spectrum of red-, green-, and blue-lights. The electricity to illuminate diodes was controlled by electrical administration transformers. Red-light was administrated by a 200-W transformer and green- and blue-lights by a 135-W transformer. Therefore, the light spectrum can be adjusted by regulating the level of electric current flows of the transformer of each light colour, and PPFD in lights given by each diode would change accordingly. For example, as shown in Table 1, reducing electrical flows to $10 \%, 10 \%$, and $70 \%$ of the full power for red-, green-, and blue-lights would create a lighting environment with a PPFD of about $95 \mu \mathrm{mol} \mathrm{m} \mathrm{s}^{-1}$ and proportions of $17.8 \%$ red-light, $33.7 \%$ green-light, and $48.5 \%$ bluelight in the visible bandwidth. This blue-enriched light can be referred to as 'R1G1B7' and looks like the wide- 
bandwidth blue-light. Similarly, the green-enriched light can be referred to as 'R2G10B3' and the red-enriched light as 'R3G1B2'. The attributes of these three spectra are shown in Table 1. The continuous curves of absolute spectrum values along 400-700 $\mathrm{nm}$ wavelengths for the three spectra are shown in Figure 1.

Table 1. The quality of spectra $40 \mathrm{~cm}$ beneath the light-emitting diode (LED) panel for three types of LED lights for the culture of Ficus hirta and Alpinia oxyphylla seedlings

\begin{tabular}{|l|c|c|c|c|}
\hline \multicolumn{1}{|c|}{ Light source } & PPFD $^{2}\left(\mu \mathrm{mol} \mathrm{m}^{-2} \mathrm{~s}^{-1}\right)$ & Red $(\%)$ & Green $(\%)$ & Blue-light $(\%)$ \\
\hline R1G1B7 ${ }^{2}$ & 95.18 & 17.8 & 33.7 & 48.5 \\
\hline R2G10B3 & & 26.2 & 56.4 & 17.4 \\
\hline R3G1B2 & 46.46 & 71.7 & 13.7 & 14.6 \\
\hline
\end{tabular}

Note: ${ }^{1}$ PPFD, photosynthetic photon flux rate; ${ }^{2}$ R1G1B7, the LED spectrum with electric current in $10 \%, 10 \%$, and $70 \%$ of the total power for red-, green-, and blue-lights, respectively; ${ }^{3} \mathrm{R} 2 \mathrm{G} 10 \mathrm{~B} 3$, the LED spectrum with electric current in $20 \%, 100 \%$, and $30 \%$ of the total power for red-, green-, and blue-lights, respectively; ${ }^{4}$ R3G1B2, the LED spectrum with electric current in $30 \%, 10 \%$, and $20 \%$ of the total power for red, green, and blue-light lights, respectively.
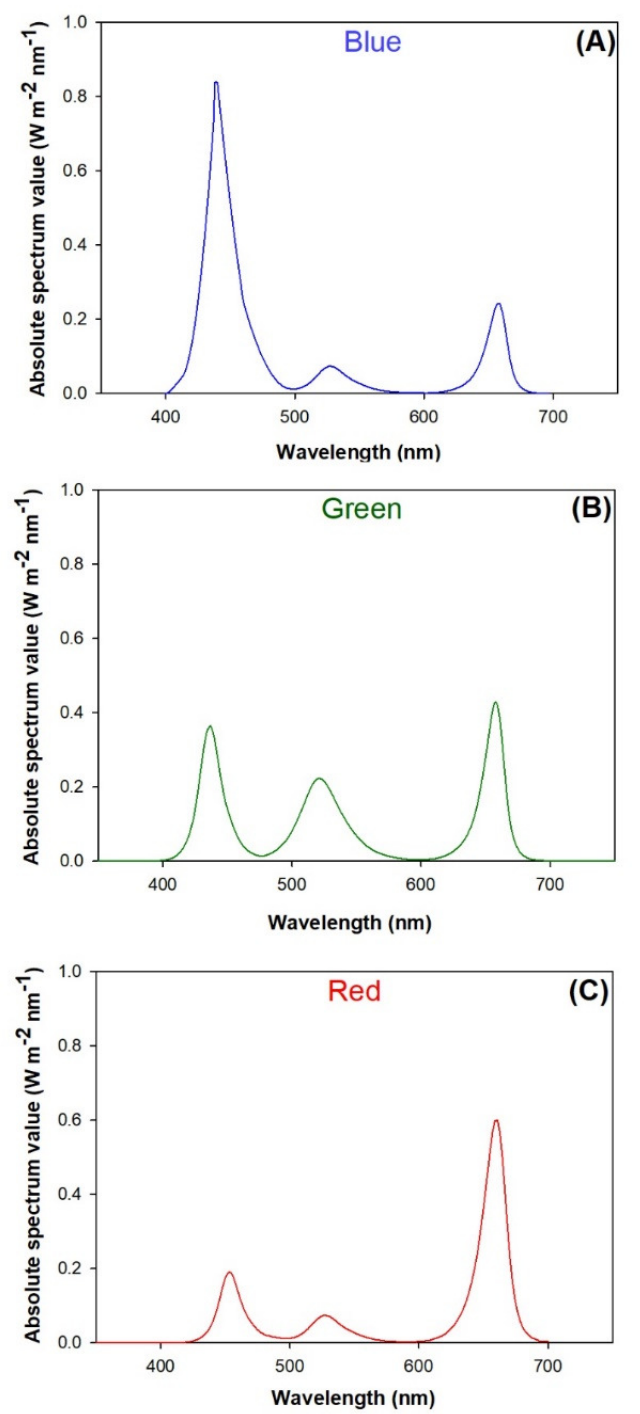

Figure 1. Continuous absolute spectrum values along wavelengths from $400 \mathrm{~nm}$ to $700 \mathrm{~nm}$ for blue (R1G1B7) (A), green (R2G10B3) (B), and red-light (R3G1B2) (C) colors in wide bandwidth 
Seedlings were subjected to an 18-h daily photoperiod from 06:00 to 24:00, which was recommended for plant cultivation (Li et al., 2017; Wei et al., 2020a; Wei et al., 2020b). From the experience of culturing another tropical medical plant, Bletilla striata (Wang et al., 2020), we created a four-month cultivation period in this study. During the experiment, seedlings were fed fertilizer according to an exponential model that was repeatedly used in previous studies for plant cultivation (Li et al., 2017; Li et al., 2018; Wei et al., 2019; Zhao et al., 2019). The exponential model in this study was set with an initial $\mathrm{N}$ content of $0.08 \mathrm{mg}$, which was $90 \%$ lower than the amount used in juvenile tree seedlings (Duan et al., 2013; Wei et al., 2013) due to biomass difference. A total of $40 \mathrm{mg} \mathrm{N}$ plant ${ }^{-1}$ of fertilizer $\left(\mathrm{N}-\mathrm{P}_{2} \mathrm{O}_{5}-\mathrm{K}_{2} \mathrm{O}, 10-7-9\right.$, self-produced formulation in nutritional solution) was applied to seedlings with one application per week for 16 weeks. This fertilizer regime promises basic nutritional needs for medical plants at a safe number of applications to avoid excessive toxicity ( Wei et al., 2013; Li et al., 2017; Wang et al., 2020). During the culturing process, temperature ranged between $28^{\circ} \mathrm{C}$ and $38^{\circ} \mathrm{C}$, and $\mathrm{RH}$ was constant around $85 \pm 1 \%$.

\section{Seedling sampling and measures}

After four months of cultivation, all seedlings were sampled at early September 2019. We found that $F$. hirta seedlings showed highly diverse leaf area; hence one seedling died out of every four adjacent ones from the shade created by the large leaves of its neighbour. Six seedlings were randomly sampled from one tray, wherein three were used to measure growth, dry-mass, and the determination of all variables on dried samples while the other three were used to measure morphology scanning and physiological determination.

Growth was assessed by measuring seedling height (the length between substrate surface and the tip of the longest natural shoot tip) and root-collar diameter (the diameter at the boundary between aerial and underground organs).

Sampled seedlings were separated into aerial and underground parts and both were oven-dried at $60^{\circ} \mathrm{C}$ for $72 \mathrm{~h}$. Dried samples were ground to pass a 1-mm sieve and measured for dry-mass biomass using a precision scale. Smashed samples were used to determine $\mathrm{N}$ and $\mathrm{P}$ concentrations, soluble sugars and starch, and total flavonoid and saponin content.

For nutritional analysis, samples, in weight of $0.2 \mathrm{~g}$ each, were placed in $5 \mathrm{~mL}$ of $99 \%(\mathrm{v} / \mathrm{v})$ hydrogen peroxide solution and $95 \%(\mathrm{v} / \mathrm{v})$ sulfuric acid solution and diluted to $50 \mathrm{mM}$. The $\mathrm{N}$ concentration was measured using the Kjeldahl method and the P concentration was measured using Inductively Coupled Plasma Optical Emission Spectrometry (Thermo Fisher Scientific, Waltham, MA, USA).

For non-structural carbohydrate (NSC) determination, a 0.5 -g leaf sample was dissolved in $50 \mathrm{~mL}$ of distilled water and steamed for $2 \mathrm{~h}$. Then, the supernatant was collected, centrifuged at 5,000 rpm for $15 \mathrm{~min}$ at $4{ }^{\circ} \mathrm{C}$, and measured for soluble sugars concentration using a spectrophotometer (UV-Visible 8453, Agilent Technologies Inc., Santa Clara, CA, USA) at a wavelength of $490 \mathrm{~nm}$. The residues were soaked twice in 15 $\mathrm{mL}$ distilled water, oven-dried at $70{ }^{\circ} \mathrm{C}$ for $1 \mathrm{~h}$, moved into a sealed test-tube with $10 \mathrm{~mL}$ of $3 \%(\mathrm{v} / \mathrm{v})$ hydrochloric acid for extraction, and maintained in boiling water for $8 \mathrm{~h}$. A volume of $1 \mathrm{~mL}$ of $28 \%$ phenol solution was added to dried samples, centrifuged at 5,000 rpm for $15 \mathrm{~min}$ at $4{ }^{\circ} \mathrm{C}$, and measured for starch concentration again at a wavelength of $490 \mathrm{~nm}$.

Total flavonoid and saponin concentrations were determined using the colorimetric method adapted from Qi et al. (2018). Three 0.1-g dried leaf samples were dissolved in $2 \mathrm{~mL}$ of $79 \%$ ethanol, ultrasonically extracted for $1 \mathrm{~h}$, and centrifuged at 4,000 rpm for $15 \mathrm{~min}$. A $10 \mathrm{ml}$ solution of supernatants dissolved with $70 \%$ ethanal received drips of $0.3 \mathrm{~mL}$ of $5 \%$ sodium nitrite. The incubation of the biochemical reaction persisted for $6 \mathrm{~min}$ and the supernatants were measured for the concentration of total flavonoids at $510 \mathrm{~nm}$ with rutin as the reacting reference. The process for determining saponins was nearly the same as that for flavonoids but with some minor differences. Briefly, a sample of 1.0-g whose lipids were removed was ultrasonically extracted with $70 \%$ ethanol for $1 \mathrm{~h}$. A volume of $50 \mu \mathrm{L}$ supernatants was resolved with $0.2 \mathrm{~mL}$ vanillin-glacial acetic acid and $0.8 \mathrm{~mL}$ perchloric acid and recorded for the absorbance at $560 \mathrm{~nm}$. 
Two leaves were randomly excised and scanned at 300 dpi (HP Deskjet 1510 scanner, HP Inc., Palo Alto, CA, USA). The image was subsequently stratified to generate a layer of leaves and a background using Photoshop CS V. 8.0 (Adobe, San Jose, CA, USA). The front layer of leaves was used to create a histogram where leaf area can be calculated as the total number of pixels for the projected image (Wei et al., 2019; Zhu et al., 2019; Wang et al., 2020). Thereafter, the specific leaf area (SLA) can be calculated as the product of leaf area and single leaf biomass. Fine root morphology was assessed using the same seedling after shoot measurement. Roots were excised and rinsed to remove attached substrates. Roots were dried using tissue papers and canned without overlap among lateral roots. Root images were analysed using WinRhizo software (Regent Instrument Inc., Calgary, Canada) to quantify fine root length, surface-area, diameter, and tipnumber.

Chlorophyll and protein concentrations were analysed by the method adapted from Zhao et al. (2019). Briefly, chlorophyll was determined using a $0.05 \mathrm{~g}$ sample that was already soaked in $2.5 \mathrm{~mL}$ of dimethyl suofoxide in the test tubes that were given a hydraulic bath at $65^{\circ} \mathrm{C}$ for $1 \mathrm{~h}$ and incubated for $24 \mathrm{~h}$. The spectrophotometer was used to determine concentrations of chlorophyll-a, chlorophyll-b, and carotenoid at wavelengths of $663 \mathrm{~nm}, 645 \mathrm{~nm}$, and $470 \mathrm{~nm}$, respectively. Protein content was measured from a 0.1-g sample that was ground in a $1 \mathrm{~mL}$ phosphate buffer with a $\mathrm{pH}$ of 7.5, centrifuged at 3,000 rpm for $10 \mathrm{~min}$, treated by $0.1 \mathrm{~mL}$ of Folin's reagent and determined at $650 \mathrm{~nm}$.

\section{Statistical analysis}

All statistics were calculated using IBM SPSS statistic software. The Shapiro-Wilk normality was tested, and no necessary transformation of data was needed. All data were analysed by two-way analysis of variance (ANOVA) with two species (F. hirta and A. oxyphylla) and three spectra (R1G1B3, RGG10B3, and R3G1B2) combined in a $2 \times 3$ factorial design of experiment with three combined replicates. When an interactive effect between species and spectra was indicated by ANOVA at the $95 \%$ probability $(\alpha=0.05)$, results were compared and arranged in one-way ANOVA with six combined species-and-spectra treatments $(n=3)$ according to Tukey test at the significant level of 0.05 . Otherwise, data was compared by one-way ANOVA following the source of variance with species $(n=2)$ or spectra $(n=3)$. Vector analysis was used to separately evaluate the nutritional statuses of seedlings exposed to different spectra for either species (Wei et al., 2020a; Wei et al., 2020b). Principle component analysis (PCA) was conducted on all variables to detect the relationship between eigenvalues of the PCs that accounted for most data variation.

\section{Results}

\section{Responses of seedling growth and morphology to spectra}

Plant species and lighting spectra had an interactive effect on shoot height $\left(F_{2,12}=8.70 ; P=0.0046\right)$ and root-collar diameter (RCD) $\left(F_{2,12}=3.97 ; P=0.0476\right)$. Shoot height was highest in $A$. oxyphylla seedlings subjected to the red-light spectrum, followed by that to the blue-light spectrum, and both were higher than the shoot height of $F$. hirta seedlings (Table 2). In contrast, RCD was highest in $F$. hirta seedlings exposed to the red-light spectrum, followed by that to the blue-light spectrum, but they were not different from the RCD of A. oxyphylla seedlings (Table 2).

Plant species and lighting spectra had an interactive effect on leaf area $\left(F_{2,12}=4.65 ; P=0.0319\right)$ and specific leaf-area (SLA) $\left(F_{2,12}=52.29 ; P<0.0001\right)$. For $F$. hirta seedlings, leaf area was largest in those subjected to the red-light spectrum but smallest in those subjected to the blue-light spectrum (Figure 2A). SLA was highest in $A$. oxyphylla seedlings exposed to blue-light and green-light spectra (Figure 2B). SLA was lower in $F$. hirta seedlings exposed to blue-light and green-light spectra than those in $A$. oxyphylla seedlings. 
Table 2. Morphological response of Ficus hirta and Alpinia oxyphylla seedlings to three types of LED spectra

\begin{tabular}{|c|c|c|c|c|c|c|}
\hline \multirow{2}{*}{ Parameters } & \multicolumn{3}{|c|}{ Ficus hirta } & \multicolumn{3}{|c|}{ Alpinia oxyphylla } \\
\hline & Blue-light ${ }^{1}$ & Green-light $^{2}$ & Red-light $^{3}$ & Blue-light & Green-light & Red-light \\
\hline Height $(\mathrm{cm})$ & $3.46 \pm 0.44 \mathrm{e}^{4}$ & $5.32 \pm 0.33 \mathrm{de}$ & $6.91 \pm 0.74 \mathrm{~cd}$ & $9.68 \pm 1.27 \mathrm{~b}$ & $8.44 \pm 0.68 \mathrm{bc}$ & $13.50 \pm 0.67 \mathrm{a}$ \\
\hline $\operatorname{RCD}^{5}(\mathrm{~cm})$ & $0.47 \pm 0.08 b$ & $0.55 \pm 0.08 \mathrm{ab}$ & $0.63 \pm 0.01 \mathrm{a}$ & $0.57 \pm 0.02 \mathrm{ab}$ & $0.51 \pm 0.02 \mathrm{ab}$ & $0.57 \pm 0.05 \mathrm{ab}$ \\
\hline $\mathrm{FRL}^{6}(\mathrm{~m})$ & $21.54 \pm 4.92 b$ & $32.50 \pm 2.57 \mathrm{a}$ & $27.45 \pm 5.50 \mathrm{ab}$ & $6.05 \pm 0.98 \mathrm{c}$ & $5.39 \pm 0.11 \mathrm{c}$ & $6 / 90 \pm 2.44 c$ \\
\hline $\operatorname{FRSA}^{7}\left(\mathrm{~cm}^{2}\right)$ & $274.4 \pm 139.5 a$ & $499.1 \pm 64.6 \mathrm{a}$ & $399.9 \pm 80.2 \mathrm{a}$ & $101.7 \pm 29.4 \mathrm{a}$ & $86.7 \pm 7.90 \mathrm{a}$ & $131.8 \pm 49.8 \mathrm{a}$ \\
\hline $\mathrm{FRD}^{8}(\mathrm{~mm})$ & $1.15 \pm 0.14 \mathrm{a}$ & $1.58 \pm 0.14 \mathrm{a}$ & $1.44 \pm 0.17 \mathrm{a}$ & $1.64 \pm 0.21 \mathrm{a}$ & $1.56 \pm 0.14 \mathrm{a}$ & $1.88 \pm 0.24 \mathrm{a}$ \\
\hline FRT $^{9}$ (units) & $523.5 \pm 21.5 a$ & $366.0 \pm 48.2 \mathrm{a}$ & $422.3 \pm 165.0 \mathrm{a}$ & $155.4 \pm 10.3 a$ & $138.9 \pm 12.0 \mathrm{a}$ & $159.1 \pm 52.4 \mathrm{a}$ \\
\hline
\end{tabular}

Note: ${ }^{1}$ blue-light, the LED spectrum with electric current in $10 \%, 10 \%$, and $70 \%$ of the total power for red-, green-, and blue-lights, respectively; ${ }^{2}$ green-light, the LED spectrum with electric current in $20 \%, 100 \%$, and $30 \%$ of the total power for red, green, and blue-light lights, respectively; ${ }^{3}$ red-light, the LED spectrum with electric current in $30 \%$, $10 \%$, and $20 \%$ of the total power for red-, green-, and blue-lights, respectively; ${ }^{4}$ Different letters in a horizontal row indicate significant difference according to Tukey test at 0.05 level across LED spectra and plant species; ${ }^{5} \mathrm{RCD}$, rootcollar diameter; ${ }^{6} \mathrm{FRL}$, fine root length; ${ }^{7} \mathrm{FRSA}$, fine root surface-area; ${ }^{8} \mathrm{FRD}$, fine root diameter; ${ }^{9} \mathrm{FRT}$, fine root tipnumber.
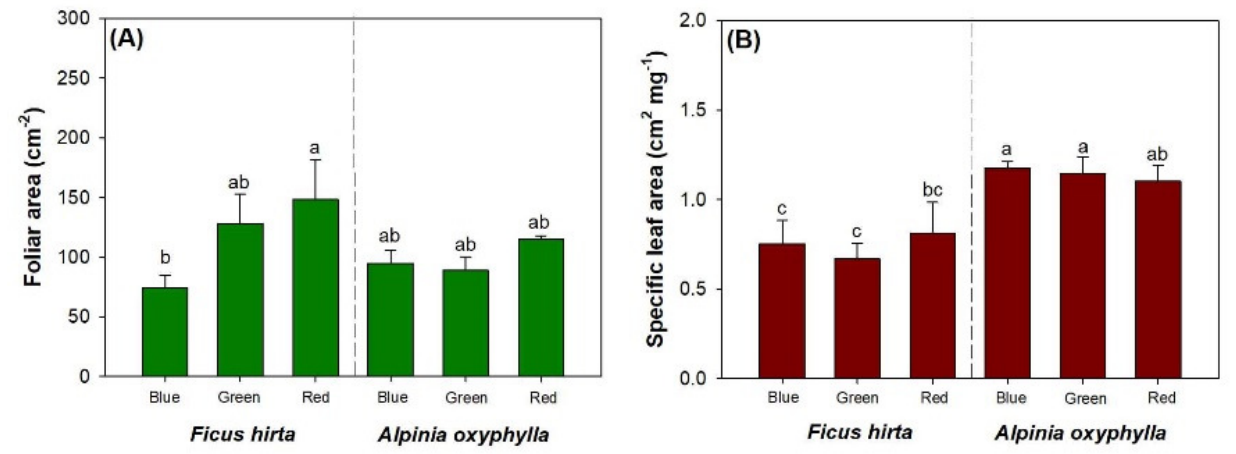

Figure 2. Foliar area (A) and specific leaf area (B) in Alpinia oxyphylla and Ficus hirta seedlings subjected to blue (R1G1B7), green (R2G10B3), and red-light (R3G1B2) spectra in wide bandwidth Different letters stand for significant difference at 0.05 level.

Plant species and lighting spectra had an interactive effect on fine root length (FRL) $\left(F_{2,12}=4.04\right.$; $P=0.0457)$. FRL was longest in $F$. hirta seedlings exposed to the green-light spectrum, followed by that to the blue-light spectrum, and both were longer than the FRL of $A$. oxyphylla seedlings (Table 2). A species-specific difference was found for fine root surface-area (FRSA) $\left(F_{1,12}=58.47 ; P<0.0001\right)$, diameter $(\mathrm{FRD})\left(F_{1,12}=11.69\right.$; $P=0.0051)$, and tip-number $(\mathrm{FRT})\left(F_{1,12}=60.04 ; P<0.0001\right)$. Ficus hirta seedlings had higher FRSA $\left(391.14 \pm 119.83 \mathrm{~cm}^{2}\right)$ and FRT (437.27 \pm 102.72 units) than $A$. oxyphylla seedlings (FRSA, $106.76 \pm 32.88 \mathrm{~cm}^{2}$; FRT, $151.10 \pm 27.20$ units) by $266 \%$ and $189 \%$, respectively. In contrast, FRD was lower in $F$. hirta seedlings $(1.39 \pm 0.21 \mathrm{~mm})$ than that in $A$. oxyphylla seedlings $(1.69 \pm 0.21 \mathrm{~mm}$ ) by $18 \%$ (Table 3$)$. 
Table 3. Physiological response of Ficus hirta and Alpinia oxyphylla seedlings to three types of LED spectra

\begin{tabular}{|c|c|c|c|c|c|c|}
\hline \multirow{2}{*}{ Parameters } & \multicolumn{3}{|c|}{ Ficus hirta } & \multicolumn{3}{|c|}{ Alpinia oxyphylla } \\
\hline & Blue-light ${ }^{1}$ & Green-light $^{2}$ & Red-light $^{3}$ & Blue-light & Green-light & Red-light \\
\hline $\mathrm{Chl}^{-\mathrm{a}^{4}}\left(\mathrm{mg} \mathrm{g}^{-1}\right)$ & $0.60 \pm 0.05 b$ & $1.57 \pm 0.44 \mathrm{a}$ & $0.68 \pm 0.12 b$ & $1.21 \pm 0.31 \mathrm{ab}$ & $1.29 \pm 0.02 \mathrm{ab}$ & $1.13 \pm 0.19 \mathrm{ab}$ \\
\hline $\mathrm{Chl}^{-\mathrm{b}^{5}\left(\mathrm{mg} \mathrm{g}^{-1}\right)}$ & $0.57 \pm 0.13 \mathrm{a}$ & $0.94 \pm 0.18 \mathrm{a}$ & $0.61 \pm 0.02 \mathrm{a}$ & $0.79 \pm 0.27 \mathrm{a}$ & $0.88 \pm 0.10 \mathrm{a}$ & $0.70 \pm 0.12 \mathrm{a}$ \\
\hline $\mathrm{Chl}-\mathrm{a} / \mathrm{b}^{6}$ & $1.09 \pm 0.20 \mathrm{a}$ & $1.69 \pm 0.50 \mathrm{a}$ & $1.12 \pm 0.16 \mathrm{a}$ & $1.58 \pm 0.17 \mathrm{a}$ & $1.48 \pm 0.18 \mathrm{a}$ & $1.62 \pm 0.07 \mathrm{a}$ \\
\hline $\mathrm{Car}^{7}\left(\mathrm{mg} \mathrm{g}^{-1}\right)$ & $0.06 \pm 0.02 b$ & $0.23 \pm 0.11 \mathrm{a}$ & $0.07 \pm 0.02 b$ & $0.15 \pm 0.03 \mathrm{ab}$ & $0.16 \pm 0.03 \mathrm{ab}$ & $0.19 \pm 0.02 \mathrm{ab}$ \\
\hline $\mathrm{TChl}^{8}\left(\mathrm{mg} \mathrm{g}^{-1}\right)$ & $1.23 \pm 0.14 \mathrm{~b}$ & $2.73 \pm 0.61 \mathrm{a}$ & $1.37 \pm 0.14 b$ & $2.15 \pm 0.58 \mathrm{ab}$ & $2.33 \pm 0.06 \mathrm{ab}$ & $2.01 \pm 0.31 \mathrm{ab}$ \\
\hline $\mathrm{SP}^{9}\left(\mathrm{mg} \mathrm{g}^{-1}\right)$ & $1.35 \pm 0.02 \mathrm{ab}$ & $1.68 \pm 0.61 \mathrm{a}$ & $1.09 \pm 0.29 \mathrm{ab}$ & $0.70 \pm 0.01 \mathrm{~b}$ & $0.73 \pm 0.03 b$ & $0.69 \pm 0.04 \mathrm{~b}$ \\
\hline $\mathrm{SS}^{10}\left(\mathrm{mg} \mathrm{g}^{-1}\right)$ & $204.5 \pm 8.8 \mathrm{a}$ & $160.5 \pm 7.3 b$ & $156.8 \pm 21.4 b$ & $154.4 \pm 17.5 b$ & $174.0 \pm 11.7 \mathrm{ab}$ & $153.1 \pm 13.6 b$ \\
\hline $\operatorname{Starch}\left(\mathrm{mg} \mathrm{g}^{-1}\right)$ & $173.1 \pm 2.6 \mathrm{a}$ & $130.6 \pm 17.5 b$ & $131.1 \pm 9.7 \mathrm{~b}$ & $159.0 \pm 10.3 \mathrm{ab}$ & $168.2 \pm 4.8 \mathrm{a}$ & $155.4 \pm 9.5 \mathrm{ab}$ \\
\hline $\operatorname{NSC}^{11}\left(\mathrm{mg} \mathrm{g}^{-1}\right)$ & $377.6 \pm 10.0 \mathrm{a}$ & $291.1 \pm 18.2 b$ & $287.9 \pm 29.6 b$ & $313.4 \pm 27.6 b$ & $342.2 \pm 7.1 \mathrm{ab}$ & $308.5 \pm 19.3 b$ \\
\hline
\end{tabular}

Note: ${ }^{1}$ blue-light, the LED spectrum with electric current in $10 \%, 10 \%$, and $70 \%$ of the total power for red-, green-, and blue-lights, respectively; ${ }^{2}$ green-light, the LED spectrum with electric current in $20 \%, 100 \%$, and $30 \%$ of the total power for red-, green-, and blue-lights, respectively; ${ }^{3}$ red-light, the LED spectrum with electric current in $30 \%, 10 \%$, and $20 \%$ of the total power for red-, green-, and blue-lights, respectively; ${ }^{4} \mathrm{Chl}-\mathrm{a}$, chlorophyll a concentration; ${ }^{5} \mathrm{Chl}-\mathrm{b}$, chlorophyll $\mathrm{b}$ concentration; ${ }^{6} \mathrm{Chl}-\mathrm{a} / \mathrm{b}$, the concentration ratio of chlorophyll a to $\mathrm{b} ;{ }^{7} \mathrm{Car}$, Carotenoid concentration; ${ }^{8} \mathrm{TChl}$, total chlorophyll concentration; ${ }^{9} \mathrm{SP}$, soluble protein; ${ }^{10} \mathrm{SS}$, soluble sugar; ${ }^{11} \mathrm{NSC}$, non-structural carbohydrate concentration.

\section{Biomass accumulation and allocation in seedlings}

Plant species and lighting spectra had an interactive effect on shoot biomass $\left(F_{2,12}=51.67 ; P<0.0001\right)$, root biomass $\left(F_{2,12}=11.20 ; P=0.0018\right)$, and root to shoot biomass ratio $(\mathrm{R} / \mathrm{S})\left(F_{2,12}=5.23 ; P=0.0233\right)$. Shoot biomass and root biomass was highest in $F$. hirta seedlings exposed to green-light and red-light spectra (Figure 3A). In contrast, $\mathrm{R} / \mathrm{S}$ was highest in $A$. oxyphylla seedlings exposed to the blue light spectrum followed by $A$. oxyphylla seedlings subjected to the blue light spectrum (Figure 3B).
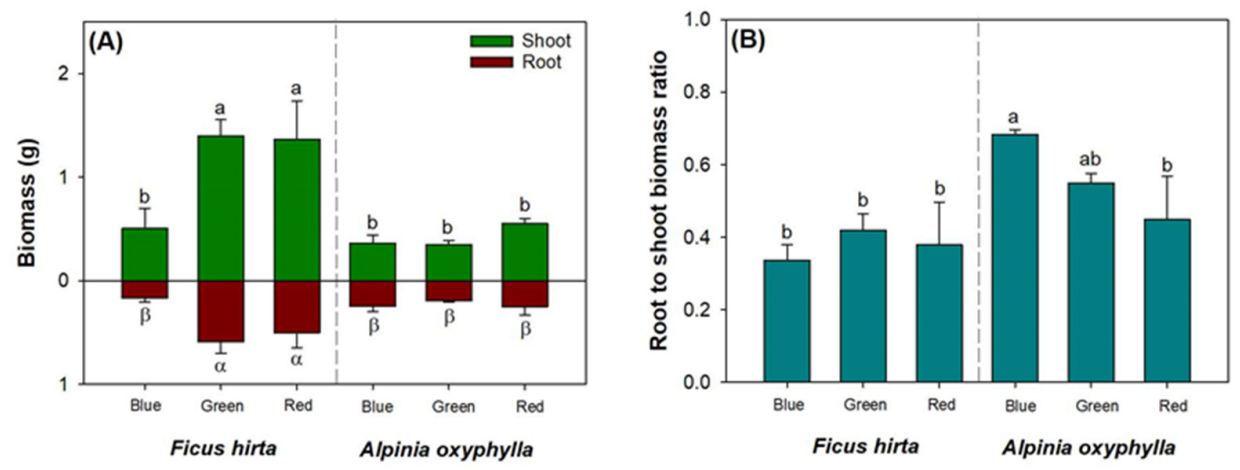

Figure 3. Shoot and root biomasses (A) and root to shoot biomass ratio (B) in Alpinia oxyphylla and Ficus hirta seedlings subjected to blue (R1G1B7), green (R2G10B3), and red-light (R3G1B2) spectra in wide bandwidth

Different letters stand for significant difference at 0.05 level. In (A), lower case letters label difference for shoot and roman letters for root.

\section{Nutrient concentration and content}

Plant species and lighting spectra had an interactive effect on $\mathrm{N}$ concentration in shoots $\left(F_{2,12}=8.03\right.$; $P=0.0061)$ and roots $\left(F_{2,12}=36.54 ; P<0.0001\right)$. Shoot $\mathrm{N}$ concentration was highest in $A$. oxyphylla seedlings subjected to the blue-light and green-light spectra, which were higher than that in $F$. hirta seedlings by $83 \%$ and $57 \%$, respectively (Figure 4A). Root N concentration of $F$. hirta subjected to light spectra, in order of greatest to least, was highest to the blue-light, followed by green-light and then red-light. Similarly, for A. oxyphylla 
seedlings, root $\mathrm{N}$ concentration was highest to the red-light spectrum followed by the green-light and blue-light spectra (Figure $4 \mathrm{~A})$.
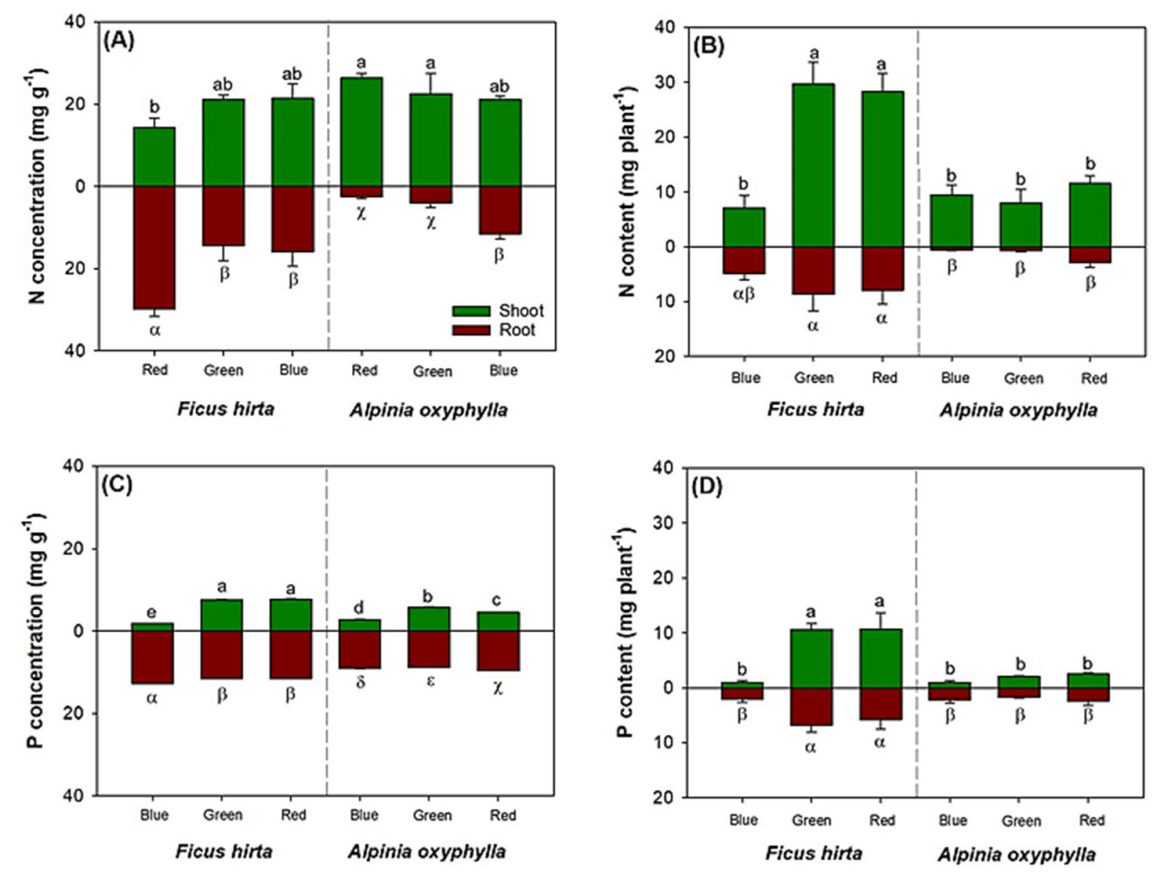

Figure 4. Nitrogen $(\mathrm{N})$ concentration $(\mathrm{A}), \mathrm{N}$ content $(\mathrm{B})$, phosphorus $(\mathrm{P})$ concentration $(\mathrm{C})$, and $\mathrm{P}$ content (B) in shoot and root parts of Alpinia oxyphylla and Ficus hirta seedlings subjected to blue (R1G1B7), green (R2G10B3), and red-light (R3G1B2) spectra in wide bandwidth

Different letters stand for significant difference at 0.05 level. Lower case letters label difference for shoot and roman letters for root.

Plant species and lighting spectra had an interactive effect on $\mathrm{N}$ content in shoots $\left(F_{2,12}=30.37\right.$; $P<0.0001)$ and roots $\left(F_{2,12}=44.65 ; P<0.0001\right)$. Shoot $\mathrm{N}$ content was highest in $F$. hirta seedlings subjected to the green-light and red-light spectra with no difference between the other treatments (Figure 4B). Root N content was highest in $F$. hirta seedlings exposed to the green-light and red-light spectra, which was higher than root $\mathrm{N}$ content in $A$. oxyphylla seedlings.

Plant species and lighting spectra had an interactive effect on $P$ concentration in shoots $\left(F_{2,12}=607.70\right.$; $P<0.0001)$ and roots $\left(F_{2,12}=240.98 ; P<0.0001\right)$. Shoot $\mathrm{P}$ concentration was highest in $F$. hirta seedlings subjected to the green-light and red-light spectra, followed by shoot $\mathrm{P}$ concentration in $A$. oxyphylla seedlings subjected to the green-light, red-light, and blue-light spectra in order of highest to lowest (Figure 4C). Shoot $\mathrm{P}$ concentration was lowest in $F$. hirta seedlings subjected to the blue-light spectrum. Root P concentration was highest in $F$. hirta seedlings subjected to the blue-light spectrum, followed by that in the green-light and redlight spectra (Figure 4C). Root $\mathrm{P}$ concentration in F. hirta seedlings was generally higher than that in $A$. oxyphylla seedlings, where P concentration declined in an order of red-light, green-light, and blue-light spectra.

Plant species and lighting spectra had an interactive effect on $\mathrm{P}$ content in shoots $\left(F_{2,12}=18.49\right.$; $P=0.0002)$ and roots $\left(F_{2,12}=10.34 ; P=0.0024\right)$. Both shoot and root $P$ contents were highest in $F$. hirta seedlings subjected to the green-light and red-light spectra (Figure 4D). 


\section{Diagnosis of nutritional status}

Compared to $A$. oxyphylla seedlings in the blue-light spectrum, those in the green-light spectrum exhibited antagonistic $\mathrm{N}$ excess and those in the red-light spectrum experienced $\mathrm{N}$ dilution (Figure 5A). For A. oxyphylla seedlings, those exposed to the red-light spectrum also experienced $\mathrm{N}$ dilution relative to those exposed to the green-light spectrum. Compared to F. hirta seedlings exposed to the blue-light spectrum, those in the green-light and red-light spectra both showed an alleviation of $\mathrm{N}$ deficiency (Figure 5A). Compared to F. hirta seedlings in the green-light spectrum, those in the red-light spectrum had a toxic amount of excess $\mathrm{N}$.
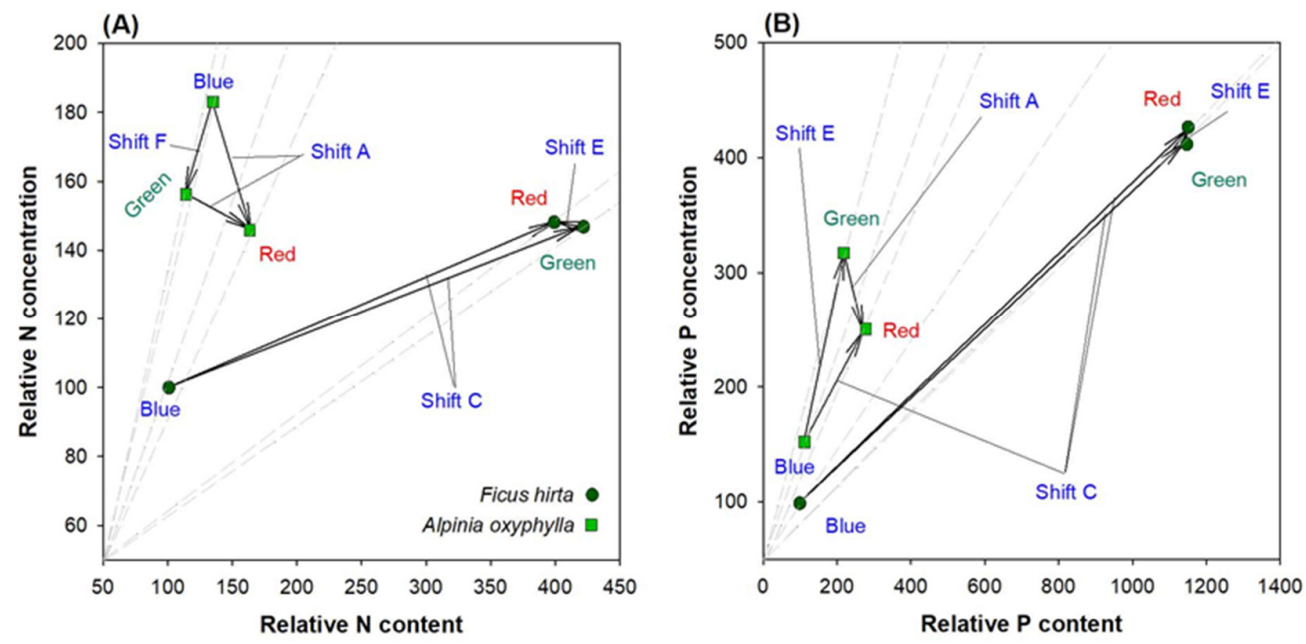

Figure 5. Vector diagnosis on nutritional status of nitrogen (N) (A) and phosphorus (P) (B) contents and concentrations in Alpinia oxyphylla and Ficus hirta seedlings subjected to blue (R1G1B7), green (R2G10B3), and red-light (R3G1B2) spectra in wide bandwidth

Interpretations for vectors are adapted from Wei et al. [6]: shift A, nutrient dilution; shift C, alleviation of nutrient deficiency; Shift E \&F, nutrient excess.

Alpinia oxyphylla seedlings in the green-light spectrum were induced toxic $\mathrm{P}$ excess relative to those in the blue-light spectrum (Figure 5B). The red-light spectrum countered P deficiency in A. oxyphylla seedlings subjected to the blue-light spectrum but elicited $\mathrm{P}$ dilution compared to those subjected to the green-light spectrum. Both green-light and red-light spectra alleviated $\mathrm{P}$ deficiency in $F$. hirta seedlings subjected to the blue-light spectrum (Figure 5B). The red-light spectrum induced toxic P excess relative to the green-light spectrum.

\section{Physiology of photosynthesis}

Plant species and lighting spectra had an interactive effect on concentrations of chlorophyll a $\left(F_{2,12}=5.34 ; P=0.0219\right)$ and carotenoid $\left(F_{2,12}=5.27 ; P=0.0227\right)$. Chlorophyll a concentration was highest in $F$. hirta seedlings exposed to the green-light spectrum, followed by those exposed to the red-light spectrum; there were no difference in chlorophyll a concentration among the rest of the treatments (Table 3). Carotenoid concentration was higher in $F$. hirta seedlings exposed to the green-light than those exposed to the blue- and red-light spectra while there was no difference among carotenoid concentrations in $A$. oxyphylla subjected to different spectra. Plant species and lighting spectra had an interactive effect on total chlorophyll concentration, which was higher in $F$. hirta seedlings exposed to the green-light spectrum than those exposed to the blue- and red-light spectra $\left(F_{2,12}=4.59 ; P=0.0331\right)$. 
Plant species and lighting spectra had an interactive effect on soluble protein concentration $\left(F_{2,12}=5.82\right.$; $P=0.0059)$. Protein concentration in $F$. hirta seedlings was higher in the green-light spectrum than in any $A$. oxyphylla seedlings.

Plant species and lighting spectra had an interactive effect on concentrations of soluble sugars $\left(F_{2,12}=7.21 ; P=0.0088\right)$, $\operatorname{starch}\left(F_{2,12}=9.30 ; P=0.0036\right)$, and non-structural carbohydrate (NSC) $\left(F_{2,12}=11.54\right.$; $P=0.0016$ ). Both soluble sugar and starch concentrations were higher in $F$. hirta seedlings exposed to the bluelight spectrum than those exposed to the green-light and red-light spectra (Table 3). Additionally, starch concentration in $A$. oxyphylla seedlings subjected to the green-light spectrum was higher than that in $F$. hirta seedlings exposed to the green-light and red-light spectra. The NSC concentration was higher in $F$. hirta seedlings exposed to the blue-light spectrum than that in the rest of the treatments except for that in $A$. oxyphylla seedlings exposed to the green-light spectrum.

\section{Secondary metabolisms}

Plant species and lighting spectra had an interactive effect on the concentration of total flavonoids $\left(F_{2,12}=4.18 ; P=0.0419\right)$. Total flavonoid concentration was higher in $A$. oxyphylla seedlings exposed to the redlight spectrum than that in the blue-light spectrum and that in $F$. hirta seedlings (Figure 6A). Plant species and lighting spectra had an interactive effect on saponin concentration $\left(F_{2,12}=15.26 ; P=0.0005\right)$. Saponin concentration was higher in $A$. oxyphylla seedlings exposed to the red- and green-light spectra than in those exposed to the blue-light spectrum and in F. hirta seedlings (Figure 6B).
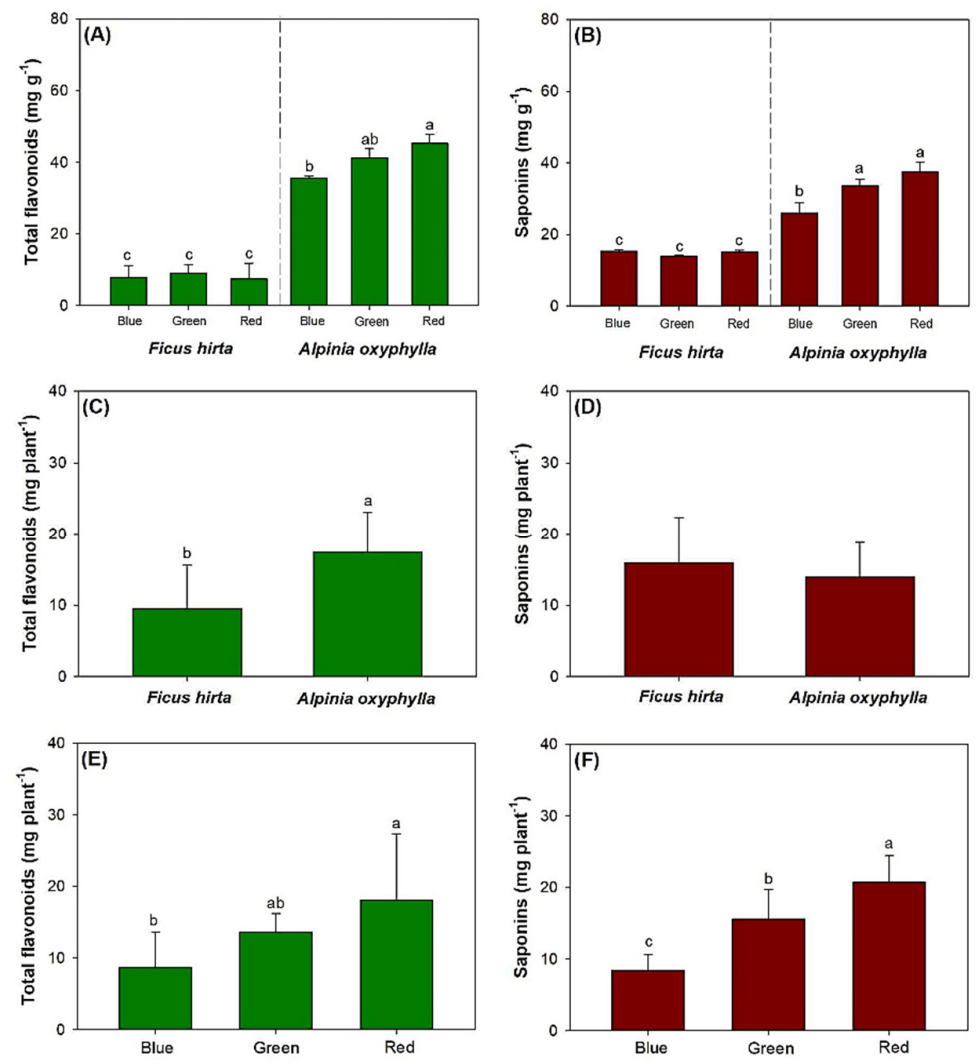

Figure 6. Total flavonoids concentration (A) and content ( $\mathrm{C}$ and $\mathrm{E})$ and saponins concentration $(\mathrm{B})$ and content (D and F) in leaves of Alpinia oxyphylla and Ficus hirta seedlings subjected to blue (R1G1B7), green (R2G10B3), and red-light (R3G1B2) spectra in wide bandwidth Different letters stand for significant difference at 0.05 level. 
Total flavonoids content had a significant response to species variation $\left(F_{1,12}=11.47 ; P=0.0054\right)$ and different spectra $\left(F_{2,12}=5.40 ; P=0.0213\right)$. Total flavonoids content in $A$. oxyphylla was higher than that in $F$. hirta by $84 \%$ (Figure 6C). Compared to the blue-light spectrum, total flavonoids content in plants exposed to the red-light spectrum were greater by $110 \%$ (Figure $6 \mathrm{E}$ ).

Saponins content had a significant response to lighting spectrum, but not species variation, which did not pass the statistics test $\left(F_{1,12}=1.76 ; P=0.2078\right)$. Saponins content was highest in the red-light spectrum, followed by that in the green- and blue-light spectra (Figure 6F).

\section{Principle component analysis across all variables}

In F. hirta seedlings, the first two principle components (PCs) accounted for $74.80 \%$ of total variance, with the first PC responsible for $59.05 \%$ and the second PC responsible for $15.74 \%$ (Figure $7 \mathrm{~A}$ ). Contents and concentrations of secondary metabolisms showed a grouped trend of eigenvalues with the exception of saponins concentration. Shoot parameters in biomass and $\mathrm{N}$ and $\mathrm{P}$ contents tended to positively relate to total flavonoids and saponins contents while photosynthetic production concentrations were inversely related. In addition, root parameters in tip number and $\mathrm{N}$ and $\mathrm{P}$ concentrations had a negative relationship with total flavonoids and saponins contents. Saponin concentration was inversely related to photosynthetic physiology and RS (Figure 7A).
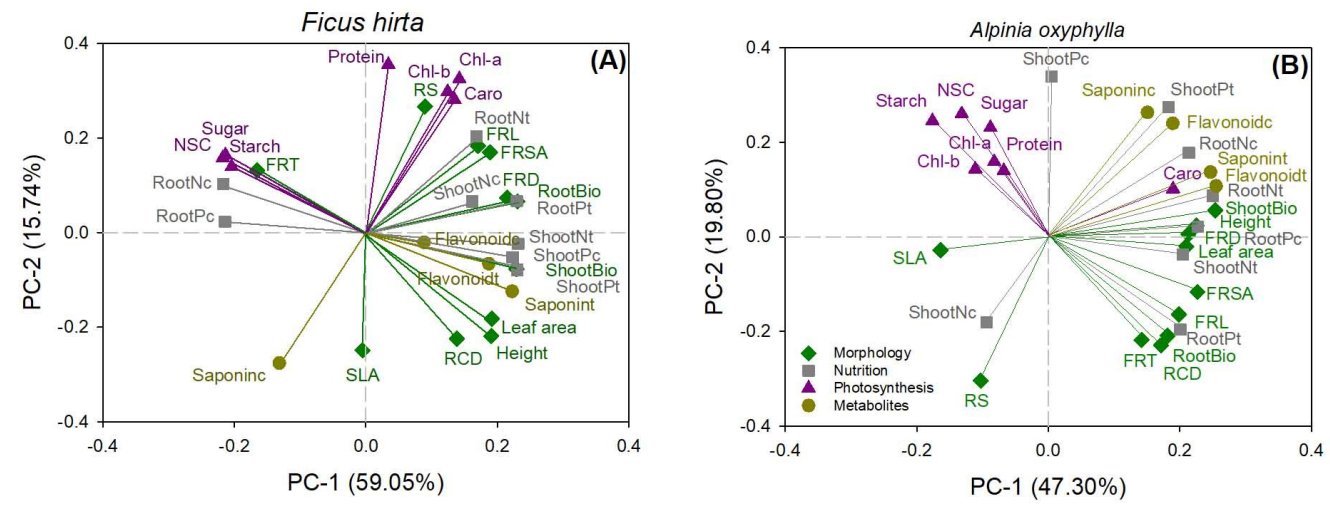

Figure 7. Principle component analysis (PCA) for variables in Alpinia oxyphylla (A) and Ficus hirta (B) seedlings subjected to blue-, green-, and red-light spectra in wide bandwidth

Abbreviations: RCD, root-collar diameter; SLA, specific leaf area; ShootBio, shoot biomass; RootBio, root biomass; RS, root to shoot biomass ratio; FRL, fine root length; FRD, fine root diameter; FRSA, fine root surface-area; FRT, fine root tip-number; Shoot $\mathrm{Nc}$, shoot $\mathrm{N}$ concentration; ShootNt, shoot $\mathrm{N}$ content; RootNc, root $\mathrm{N}$ concentration; RootNt, root N content; ShootPc, shoot P concentration; ShootPt, shoot P content; RootPc, root P concentration; RootPt, root P content; Chl-a, chlorophyll a concentration; Chl-b, chlorophyll b concentration; Caro, carotenoid concentration; Protein, protein concentration; Sugar, soluble sugars concentration; Starch, starch concentration; NSC, non-structural carbohydrate; Flavonoidc, the concentration of total flavonoids; Flavonoidt, total flavonoids content; Saponinc, saponins concentration; Saponint, saponins content.

The first two principle components (PCs) accounted for $67.10 \%$ of cumulative eigenvalues, wherein the first and second PCs explained $47.30 \%$ and $19.80 \%$ proportions in total variance, respectively (Figure 7B). Total flavonoids and saponins concentrations tended to positively relate to shoot P content. Secondary metabolism contents were positively related to root $\mathrm{N}$ content but inversely related to SLA (Figure 7B). 


\section{Discussion}

\section{Growth, morphology, and biomass accumulation}

Seedling growth showed distinct responses to these two spectra in this study and the red-light spectrum tended to induce greater shoot growth relative to the blue-light light spectrum for both species. Both height and diameter were higher in red-light spectrum than in the blue-light light spectrum for $F$. hirta seedlings, while only height was higher for $A$. oxyphylla seedlings. Red-light spectrum was also reported to result in greater height growth relative to the blue-light light spectrum for three Mentha species (Sabzalian et al., 2014) and for foxglove (Rehmannia glutinosa) (Manivannan et al., 2015). Yu et al. (2017) summarized former studies and concluded that red-light spectrum promoted plant growth through the development of photosynthetic apparatuses and inhibition of starch translocation. In addition, red-light spectrum was found to promote foliar development through increased leaf area and SLA for Camptotheca acuminate seedlings (Yu et al., 2017). Our results on foliar development partly concurs to findings as F. hirta seedlings in red-light spectrum had greater leaf area than those in blue-light light spectrum, but no difference was observed regarding SLA. Additionally, when exposed to the red-light spectrum, $F$. hirta seedlings' shoot biomass was greater and $A$. oxyphylla's R/S was promoted. We found that $A$. oxyphylla seedlings had overall greater SLA than $F$. hirta seedlings and $A$. oxyphylla seedlings exposed to red-light tended to have a greater number of leaves, although it was not counted. Therefore, the promotion of the red-light spectrum over the blue-light spectrum was due to its effects on foliar development. This effect was achieved by way of biomass accumulation and allocation as a species-specific influence. F. hirta seedlings in red-light spectrum had greater biomass production and accumulation in shoots, but biomass allocation in $A$. oxyphylla seedlings in red-light spectrum was inhibited.

The red-light spectrum did not significantly affect shoot growth compared to other spectra with the exception of $A$. oxyphylla seedlings subjected to the green-light spectrum which had shorter shoot length than those subjected to the red-light spectrum. These results are reasonable because green-light was found to slow down or even stop plant processes through cryptochrome-dependent and cryptochrome-independent means (Folta and Maruhnich, 2007). Kang et al. (2016) found several instances where green-light spectrum benefited photosynthesis and growth in several plant species. However, their results also detailed negative effects of greenlight spectrum on lettuce plants. Therefore, we conclude that green-light spectrum negatively affected the height growth of $A$. oxyphylla seedlings.

The fine roots of $F$. hirta seedlings in the green-light spectrum were longer than those in the blue-light spectrum. This concurs with a study on Bletilla striata seedlings which recorded accordant responses of fine root length and root biomass (Wang et al., 2020). For $F$. hirta seedlings, R/S was affected by lighting spectra. Hence, the longer fine roots were a result of greater biomass production. We did not consider this to be the effect of the green-light spectrum. Instead, we surmise that the inhibition of biomass production by the bluelight spectrum impaired fine root morphology.

Thus, we can only partly accept our first hypothesis because our results showed that the red-light spectrum did promote shoot growth but only when compared to the blue-light spectrum. We cannot agree to the latter half of our first hypothesis because green-light spectrum did not impair the most. Instead, it was the blue-light light spectrum that mostly negatively affected growth, biomass, and root morphology.

\section{Nutritional status establishment}

F. hirta seedlings exposed to the blue-light spectrum have higher $\mathrm{N}$ and $\mathrm{P}$ concentrations in roots compared to those exposed to the red-and green-light spectra, but nutrient concentration was also generally lower. $A$. oxyphylla seedlings rarely showed significant responses of $\mathrm{N}$ concentration in shoots to different spectra and $\mathrm{P}$ concentration was higher in the green-light spectra. Therefore, blue-light can reduce $\mathrm{N}$ and $\mathrm{P}$ concentrations in shoots. We fail to find similar results that can be referred to for this part of our results, but evidence revealed that blue-light spectrum can reduce foliar $\mathrm{N}$ concentration by synthesizing $\mathrm{NH}_{4}^{+}$into glutamine with enhanced glutamine synthetase activity (Elmlinger and Mohr, 1992; Zhang et al., 2018). 
Studies also found that blue-light spectrum induces the stomatal to open which inhibits the inhibitors of calyculin A and okadaic acid of protein phosphatases (Kinoshita and Shimazaki, 1997). The phosphatase activity may have been upregulated under blue-light which reduced shoot $\mathrm{P}$ concentration by promoting $\mathrm{P}$ assimilation. More conclusive results require future studies to confirm the assessment of $\mathrm{N}$ and $\mathrm{P}$ assimilations.

Plant nutritional status refers to the synthesized symptom that is exposed under drivers of biomass accumulation and nutrient assimilation ( Xu et al., 2019; Wei et al., 2020b). Several studies have fully demonstrated that the variation in lighting spectra can shape plant nutritional statuses by modifying nutrient uptake, allocation, and utilization (Li et al., 2017; Li et al., 2018; Zhao et al., 2019; Wang et al., 2020; Wei et al., 2020a; Wei et al., 2020b). In our study, it was interesting to find a highly species-specific response to differences in lighting spectra. The green-light and red-light spectra in the respective green and red-lights both revealed the alleviation of $\mathrm{N}$ and $\mathrm{P}$ deficiencies in F. hirta seedlings exposed to the R1G1B7 spectrum of bluelight. However, in $A$. oxyphylla seedlings, the green-light spectrum resulted in $\mathrm{N}$ and $\mathrm{P}$ excesses while the redlight spectrum led to dilutions. The relatively negative impact from the green-light spectrum in comparison to the blue-light spectrum resulted from the decline of biomass despite how much $\mathrm{N}$ and $\mathrm{P}$ were absorbed; meanwhile, the relative impairment from the red-light spectrum was caused by the decrease of $\mathrm{N}$ and $\mathrm{P}$ concentrations in spite of the dual increases in biomass and content.

Our results on the nutritional response of $F$. hirta seedlings to red-light, in a range of spectra from low to high proportions, generally concur the nutritional responses of Bletilla striata (Wang et al., 2020) and Pinus koraiensis (Wei et al., 2020b). On the other hand, our results on the nutritional response of $A$. oxyphylla seedlings to different spectra concur with the responses of Dalbergia odorifera (Li et al., 2018) and Aralia elata (Wei et al., 2020a). Given that $F$. hirta seedlings have large leaves that can fully receive photons emitted from LED panels, it appears that plants with a foliar phenotype allowing greater exposure to light perform better in spectrums with higher red-light proportion. Although pine seedlings have needle-like leaves that have small light-exposure area, the abundance of needles account for a high accumulative light-exposure. We notice that the foliar phenotypes of $A$. oxyphylla, $D$. odorifera, and $A$. elata all result in leaves that sprout at different verticillate depths. Only parts of the leaves in this phenotype can function to receive photosynthesis. Therefore, when biomass production was accelerated by red-light spectrum, nutrient uptake could not catch up. In contrast, when nutrient uptake and utilization were enhanced by green-light spectrum, biomass accumulation could not catch up with growth. Further studies are needed in the future to compare the response of plants with different foliar phenotypes to lighting spectra.

\section{Secondary metabolisms}

Flavonoids and saponins are commonly used secondary metabolites in medicinal plants and are also responsible for the medicinal uses of the two plants tested in this study (Niu et al., 2020; Ya et al., 2010). In our study, $A$. oxyphylla seedlings were found to produce greater total flavonoids and saponins per unit biomass than F. hirta seedlings. It was interesting to find that both contents and concentrations for the two secondary metabolisms increased as red-light proportions increased. This disagreed with our second hypothesis because red-light spectrum surpassed blue-light spectrum in secondary metabolism accumulation and green-light spectrum was not superior. In contrast, studies found that blue-light spectrum can benefit the synthesis of total flavonoids because of the significant accumulation of major flavonoid components ( Taulavuori et al., 2016; Nam et al., 2018). Another study also reported that red-light spectrum needed salicylic acid to induce flavonoid synthesis (Ni et al., 2018). However, most former studies on the effects of lighting spectra on flavonoids accumulation were conducted on narrow bandwidth lights, which had only a partial effect on flavonoids synthesis (Zhao et al., 2020). Instead, the wide bandwidth spectrum comprising both red- and blue-light wavelengths had greater impact (Zhao et al., 2020). Because we employed a wide bandwidth, our results are more reliable.

It was interesting to find that the content of secondary metabolisms had a positive relationship with

shoot $\mathrm{P}$ concentration and content in $F$. hirta seedlings, and secondary metabolisms concentrations also had a 
positive relationship with shoot $\mathrm{P}$ content in A. oxyphylla seedlings. According to Pedone-Bonfim et al. (2013), the synthesis of secondary metabolisms in medicinal plants strongly rely on P availability. This may be because medicinal plants are usually acclimated to $\mathrm{P}$ deficiency in their natural habitat, which made $\mathrm{P}$ a necessary element for their bioactive activities. In addition, $\mathrm{P}$ concentration had a similar response to $\mathrm{P}$ content in reaction to different spectra, which supports our surmise and suggests that $\mathrm{P}$ uptake was also needed in biomass accumulation for synchronized pacing. The negative relationship between saponin concentration and chlorophyll concentration may be the result of contrasting conditions that preconditioned their synthesis (Golawska et al., 2010; Ma et al., 2019). Stressed conditions benefit the synthesis of secondary metabolism but unstressed conditions benefit the synthesis of chlorophyll.

\section{Conclusions}

In this study, we tested the response of two medicinal plants, F. hirta and $A$. oxyphylla, to different spectra from wide bandwidth red-, green-, and blue-lights. Generally, lighting spectra had an interactive effect with species on medicinal plants. The blue-light spectrum negatively impacted $F$. hirta. The red-light spectrum resulted in an abundant accumulation of secondary metabolisms in $A$. oxyphylla. We did not find special effect of the green-light spectrum on the two plants that was different from the red-and blue-light spectra. Therefore, A. oxyphylla has more potential than $F$. hirta to produce natural secondary metabolisms in leaves using the wide bandwidth spectrum of red-light.

\section{Authors' Contributions}

Conceptualization, C.Z.; Supervision, L.Y.; Funding acquisition, C.Z., L.Y. and P.G.; data curation, C.Z. and C.S.; Investigation, C.Z., C.S. and J.B.; Formal analysis, F.C. and J.B.; Methodology, C.Z.; Project administration, L.Y. and P.G.; Resources, C.Z., C.S. and J.B.; Validation, C.Z.; Visualization, C.Z.; Writingoriginal draft preparation, C.Z.; writing-review and editing, L.Y. and P.G. All authors have read and agreed to the published version of the manuscript.

All authors read and approved the final manuscript.

\section{Acknowledgements}

This research was supported by Science and Technology Projects of Guizhou Province (grant number: Qian Ke He Foundation [2018] 1045, Qian Ke He Platform Talent [2017] 5788, Qian Ke He Platform Talent [2018] 5781), National Natural Science Foundation of China (grant numbers: 41861017; 31771695), Construction Program of Biology First-class Discipline in Guizhou (grant number: GNYL [2017] 009), and Fundamental Research Funds for the Central Universities (Program for ecology research group) (grant number: 0901-110109).

\section{Conflict of Interests}

The authors declare that there are no conflicts of interest related to this article. 


\section{References}

Ballare CL (2014). Light regulatoin of plant defense. Annual Review of Plant Biology 65:335-363. https://doi.org/10.1146/annurev-arplant-050213-040145

Bhardwaj P, Jain CK, Mathur A (2019). Comparative analysis of saponins, flavonoids, phenolics and antioxidant activities of field acclimatized and in vitro propagated Bacopa monnieri (L.) Pennell from different locations in India. Indian Journal of Experimental Biology 57(4):259-268. https://doi.org/handle/123456789/46928

Claypool NB, Lieth JH (2020). Physiological responses of pepper seedlings to various ratios of blue, green, and red light using LED lamps. Scientia Horticulturae 268:10. https://doi.org/10.1016/j.scienta.2020.109371

Duan J, Xu CY, Jacobs DF, Ma LY, Wei HX, Jiang LN, Ren J (2013). Exponential nutrient loading shortens the cultural period of Larix olgensis seedlings. Scandinavian Journal of Forest Research 28(5):409-418. https://doi.org/10.1080/02827581.2013.778328

Elmlinger MW, Mohr H (1992). Glutamine synthetase in Scots pine seedlings and its control by blue light and light absorbed by phytochrome. Planta 188(3):396-402. https://doi.org/10.1007/BF00192807

Folta KM, Maruhnich SA (2007). Green light: a signal to slow down or stop. Journal of Experimental Botany 58(12):3099-3111. https://doi.org/10.1093/jxb/erm130

Golawska S, Krzyzanowski R, Lukasik I (2010). Relationship between aphid infestation and chlorophyll content in Fabaceae species. Acta Biologica Cracoviensia Series Botanica 52(2):76-80. https://doi.org/10.2478/v10182-0100026-4

Holopainen JK, Kivimaenpaa M, Julkunen-Tiitto R (2018). New light for phytochemicals. Trends in Biotechnology 36(1):7-10. https://doi.org/10.1016/j.tibtech.2017.08.009

Kang WH, Park JS, Park KS, Son JE (2016). Leaf photosynthetic rate, growth, and morphology of lettuce under different fractions of red, blue, and green light from light-emitting diodes (LEDs). Horticulture Environment and Biotechnology 57(6):573-579. https://doi.org/10.1007/s13580-016-0093-X

Kinoshita T, Shimazaki K (1997). Involvement of calyculin A- and okadaic acid-sensitive protein phosphatase in the blue light response of stomatal guard cells. Plant and Cell Physiology 38(11):1281-1285. https://doi.org/10.1093/oxfordjournals.pcp.a029117

Landi M, Zivcak M, Sytar O, Brestic M, Allakhverdiev SI (2020). Plasticity of photosynthetic processes and the accumulation of secondary metabolites in plants in response to monochromatic light environments: A review. Biochimica Et Biophysica Acta-Bioenergetics 1861(2):24. https://doi.org/10.1016/j.bbabio.2019.148131

Li XW, Chen QX, Lei HQ, Wang JW, Yang S, Wei HX (2018). Nutrient uptake and utilization by fragrant rosewood (Dalbergia odorifera) seedlings cultured with oligosaccharide addition under different lighting spectra. Forests 9(1):15. https://doi.org/10.3390/f9010029

Li XW, Gao Y, Wei HX, Xia HT, Chen QX (2017). Growth, biomass accumulation and foliar nutrient status in fragrant rosewood (Dalbergia odorifera TC Chen) seedlings cultured with conventional and exponential fertilizations under different photoperiod regimes. Soil Science and Plant Nutrition 63(2):153-162. https://doi.org/10.1080/00380768.2017.1312518

Luo YQ, Zhao SJ, Tang JY, Zhu H, Wei HX, Cui W, Wang MH, Guo P (2020). White-light emitting diodes' spectrum effect on photosynthesis and nutrient use efficiency in Podocarpus macrophyllus seedlings. Journal of Plant Nutrition 9. https://doi.org/10.1080/01904167.2020.1798999

Ma XH, Qian RJ, Zhang XL, Hu QD, Liu HJ, Zheng J (2019). Contrasting growth, physiological and gene expression responses of Clematis crassifolia and Clematis cadmia to different irradiance conditions. Scientific Reports 9:12. https://doi.org/10.1038/s41598-019-54428-Z

Manivannan A, Soundararajan P, Halimah N, Ko CH, Jeong BR (2015). Blue LED light enhances growth, phytochemical contents, and antioxidant enzyme activities of Relunannia glutinosa cultured in vitro. Horticulture Environment and Biotechnology 56(1):105-113. https://doi.org/10.1007/s13580-015-0114-1

Nam TG, Kim DO, Eom SH (2018). Effects of light sources on major flavonoids and antioxidant activity in common buckwheat sprouts. Food Science and Biotechnology 27(1):169-176. https://doi.org/10.1007/s10068-017-02041

Ni J, Dong LX, Jiang ZF, Yang XL, Sun ZH, Li JX, ... Xu MJ (2018). Salicylic acid-induced flavonoid accumulation in Ginkgo biloba leaves is dependent on red and far-red light. Industrial Crops and Products 118:102-110. https://doi.org/10.1016/j.indcrop.2018.03.044 
Nishio JN (2001). Why are higher plants green? Evolution of the higher plant photosynthetic pigment complement. Plant, Cell \& Environment 23:539-548. https://doi.org/10.1046/j.1365-3040.2000.00563.x

Niu Q, Gao YM, Liu PH (2020). Optimization of microwave-assisted extraction, antioxidant capacity, and characterization of total flavonoids from the leaves of Alpinia oxyphylla Miq. Preparative Biochemistry \& Biotechnology 50(1):82-90. https://doi.org/10.1080/10826068.2019.1663535

Pedone-Bonfim MVL, Lins MA, Coelho IR, Santana AS, Silva FSB, Maia LC (2013). Mycorrhizal technology and phosphorus in the production of primary and secondary metabolites in cebil (Anadenanthera colubrina (Vell.) Brenan) seedlings. Journal of the Science of Food and Agriculture 93(6):1479-1484. https://doi.org/10.1002/jsfa.5919

Pennisi G, Pistillo A, Orsini F, Cellini A, Spinelli F, Nicola S, ... Marcelis LFM (2020). Optimal light intensity for sustainable water and energy use in indoor cultivation of lettuce and basil under red and blue LEDs. Scientia Horticulturae 272:10. https://doi.org/10.1016/j.scienta.2020.109508

Qi MM, Hua XY, Peng XY, Yan XF, Lin JX (2018). Comparison of chemical composition in the buds of Aralia elata from different geographical origins of China. Royal Society Open Science 5(8):10. https://doi.org/10.1098/rsos. 180676

Rehman M, Ullah S, Bao YN, Wang B, Peng DX, Liu LJ (2017). Light-emitting diodes: whether an efficient source of light for indoor plants? Environmental Science and Pollution Research 24(32):24743-24752. https://doi.org/10.1007/s11356-017-0333-3

Sabzalian MR, Heydarizadeh P, Zahedi M, Boroomand A, Agharokh M, Sahba MR, Schoefs B (2014). High performance of vegetables, flowers, and medicinal plants in a red-blue LED incubator for indoor plant production. Agronomy for Sustainable Development 34(4):879-886. https://doi.org/10.1007/s13593-014-0209-6

Stankovic J, Godevac D, Tesevic V, Dajic-Stevanovic Z, Ciric A, Sokovic M, Novakovic M (2019). Antibacterial and antibiofilm activity of flavonoid and saponin derivatives from Atriplex tatarica against Pseudomonas aeruginosa. Journal of Natural Products 82(6):1487-1495. https://doi.org/10.1021/acs.jnatprod.8b00970

Taulavuori K, Hyoky V, Oksanen J, Taulavuori E, Julkunen-Tiitto R (2016). Species-specific differences in synthesis of flavonoids and phenolic acids under increasing periods of enhanced blue light. Environmental and Experimental Botany 121:145-150. https://doi.org/10.1016/j.envexpbot.2015.04.002

Terashima I, Fujita T, Inoue T, Chow WS, Oguchi R (2009). Green light drives leaf photosynthesis more efficiently than red light in strong white light: revisiting the enigmatic question of why leaves are green. Plant and Cell Physiology 50:684-697. https://doi.org/10.1093/pcp/pcp034

Wan FF, Ross-Davis AL, Davis AS, Song XH, Chang XC, Zhang J, Liu Y (2020). Nutrient retranslocation in Larix principis-rupprechtii Mayr relative to fertilization and irrigation. New Forests https://doi.org/10.1007/s11056020-09783-5

Wan FF, Ross-Davis AL, Shi WH, Weston C, Song XH, Chang XC, ... Teng F (2019). Subirrigation effects on larch seedling growth, root morphology, and media chemistry. Forests 10(1):14. https://doi.org/10.3390/f10010038

Wang R, Wang Y, Su Y, Tan JH, Luo XT, Li JY, He Q (2020). Spectral effect on growth, dry mass, physiology and nutrition in Bletilla striata seedlings: Individual changes and collaborated response. International Journal of Agriculture and Biology 24(1):125-132. https://doi.org/10.17957/ijab/15.1416

Watcharatanon K, Ingkaninan K, Putalun W (2019). Improved triterpenoid saponin glycosides accumulation in in vitro culture of Bacopa monnieri (L.) Wettst with precursor feeding and LED light exposure. Industrial Crops and Products 134:303-308. https://doi.org/10.1016/j.indcrop.2019.04.011

Wei HX, Chen GS, Chen X, Zhao HT (2020a). Growth and nutrient uptake in Aralia elata seedlings exposed to exponential fertilization under different illumination spectra. International Journal of Agriculture and Biology 23(3):644-652. https://doi.org/10.17957/ijab/15.1336

Wei HX, Chen X, Chen GS, Zhao HT (2019). Foliar nutrient and carbohydrate in Aralia elata can be modified by understory light quality in forests with different structures at Northeast China. Annals of Forest Research 62(2):125-137. https://doi.org/10.15287/afr.2019.1395

Wei HX, Hauer RJ, Chen GS, Chen X, He XY (2020b). Growth, nutrient assimilation, and carbohydrate metabolism in Korean pine (Pinus koraiensis) seedlings in response to light spectra. Forests 11(1):18. https://doi.org/10.3390/f11010044

Wei HX, Ren J, Zhou JH (2013). Effect of exponential fertilization on growth and nutritional status in Buddhist pine (Podocarpus macrophyllus Thunb. D. Don) seedlings cultured in natural and prolonged photoperiods. Soil Science and Plant Nutrition 59(6):933-941. https://doi.org/10.1080/00380768.2013.864957 
Wei HX, Zhao HT, Chen X (2019). Foliar N:P stoichiometry in Aralia elata distributed on different slope degrees. Notulae Botanicae Horti Agrobotanici Cluj-Napoca 47(3):887-895. https://doi.org/10.15835/nbha47311390

World Health Organization (2013). WHO Traditional Medicine Strategy: 2014-2013. Geneva, Switzerland: World Health Organization.

Xu L, Zhang X, Zhang DH, Wei HX, Guo J (2019). Using morphological attributes for the fast assessment of nutritional responses of Buddhist pine (Podocarpus macrophyllus Thunb. D. Don) seedlings to exponential fertilization. Plos One 14(12):14. https://doi.org/10.1371/journal.pone.0225708

Ya J, Zhang XQ, Wang Y, Zhang QW, Chen JX, Ye WC (2010). Two new phenolic compounds from the roots of Ficus hirta. Natural Product Research 24(7):621-625. https://doi.org/10.1080/14786410902847377

Yan ZN, He DX, Niu GH, Zhou Q, Qu YH (2020). Growth, nutritional quality, and energy use efficiency in two lettuce cultivars as influenced by white plus red versus red plus blue LEDs. International Journal of Agricultural and Biological Engineering 13(2):33-40. https://doi.org/10.25165/j.ijabe.20201302.5135

Yu WW, Liu Y, Song LL, Jacobs DF, Du XH, Ying YQ, ... Wu JS (2017). Effect of differential light quality on morphology, photosynthesis, and antioxidant enzyme activity in Camptotheca acuminata seedlings. Journal of Plant Growth Regulation 36(1):148-160. https://doi.org/10.1007/s00344-016-9625-y

Zhang T, Shi YY, Piao FZ, Sun ZQ (2018). Effects of different LED sources on the growth and nitrogen metabolism of lettuce. Plant Cell Tissue and Organ Culture 134(2):231-240. https://doi.org/10.1007/s11240-018-1415-8

Zhao J, Chen X, Wei HX, Lv J, Chen C, Liu XY, ... Jia LM (2019). Nutrient uptake and utilization in Prince Rupprecht's larch (Larix principis-rupprechtii Mayr.) seedlings exposed to a combination of light-emitting diode spectra and exponential fertilization. Soil Science and Plant Nutrition 65(4):358-368. https://doi.org/10.1080/00380768.2019.1631715

Zhao J, Thi LT, Park YG, Jeong BR (2020) Light quality affects growth and physiology of carpesium triste Maxim. cultured in vitro. Agriculture-Basel 10(7):19. https://doi.org/10.3390/agriculture10070258

Zu YQ, Mei XY, Li B, Li T, Li Q, Qin L, Yang ZQ (2020) Effects of calcium application on the yields of flavonoids and saponins in Panax notoginseng under cadmium stress. International Journal of Environmental Analytical Chemistry 12. https://doi.org/10.1080/03067319.2020.1781835
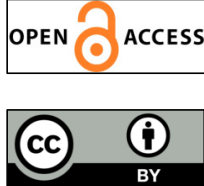

The journal offers free, immediate, and unrestricted access to peer-reviewed research and scholarly work. Users are allowed to read, download, copy, distribute, print, search, or link to the full texts of the articles, or use them for any other lawful purpose, without asking prior permission from the publisher or the author.

License - Articles published in Notulae Botanicae Horti Agrobotanici Cluj-Napoca are Open-Access, distributed under the terms and conditions of the Creative Commons Attribution (CC BY 4.0) License. (c) Articles by the authors; UASVM, Cluj-Napoca, Romania. The journal allows the author(s) to hold the copyright/to retain publishing rights without restriction. 